\section{No Support for the Watching Eyes Effect Across Three "Lost Letter" Field Experiments}

\author{
Zoi Manesi ${ }^{1,2,}$, Thomas V. Pollet ${ }^{1,3}$ \\ ${ }^{1}$ Social and Organizational Psychology, Department of Experimental and \\ Applied Psychology, Faculty of Behavioural and Movement Sciences, Vrije \\ Universiteit Amsterdam, Amsterdam, The Netherlands \\ ${ }^{2}$ School of Social Sciences, Singapore Management University, 90 Stamford \\ Road, Singapore 178903 \\ ${ }^{3}$ Department of Social and Organizational Psychology, Faculty of Social \\ and Behavioural Sciences, Leiden University, Leiden, The Netherlands \\ *Author for correspondence (zoi@zoimanesi.com)
}

The watching eyes effect has been hotly debated in recent years. Interestingly, field studies often reveal strong effects of eye images on various forms of prosociality. Here, we explored the watching eyes effect on prosociality - in terms of lost letter return rates. We conducted three field experiments, in which we dropped a total of 540 letters in 13 different neighborhoods in the Netherlands (six of high socioeconomic status (SES) and seven of low SES). The envelopes had printed stylized eyes, flowers (or no logo, for Experiments 1 and 2). Combined analysis of all three experiments revealed no significant effect of eye images on lost letter return rates. There was also no interaction between eyes and SES but also no main effect of SES levels on lost letter return rates. Overall, these null results suggest that minimal cues to being watched may not be that powerful in promoting forms of prosociality that entail a certain cost and do not have obvious benefits for the individual, such as return of lost letters.

\section{Keywords}

watching eyes effect, prosociality, reputation, field experiments

\section{Introduction}

The watching eyes effect has been subject to vigorous debate. A number of studies have provided compelling evidence that eye images can enhance prosociality (for a meta-analysis, see Sparks \& Barclay, 2013). Yet, other research provides no support for an effect (for a more recent meta-analysis of studies on generosity, see Northover, Pedersen, Cohen, \& Andrews, 2017). Interestingly, when eye images do modulate human behavior, the strongest effects are usually documented in field settings. For instance, placing eye images in various public settings has been shown to promote behaviors such as charitable giving (Oda \& Ichihashi, 2016; Powell, Roberts, \& Nettle, 2012), litter clean up (Bateson et al., 2015), abidance by honesty systems (Bateson, Nettle, \& Roberts, 2006), compliance with the law (Nettle, Nott, \& Bateson, 2012) and propensity to vote in elections (Panagopoulos \& Van der Linden, 2016), to name just a few effects.

However, up until now, most of the field research on the watching eyes effect has focused on cooperative and prosocial behaviors that are relatively normative (e.g., cleaning up one's own litter). For such types of normative behavior, being watched should matter because it serves as a reminder of how one is expected to behave in such ordinary situations. Thus, it is possible that showing prosocial behavior in those situations is habitual and the perceived responsibility (for violating such expectations) is relatively high. An eye image in such cases may serve as a cue to social rewards (or sanctions) that could potentially be imposed for socially appropriate (or inappropriate) behaviors. Yet, it is unclear whether eye images can affect forms of prosociality that are less habitual or that may not have obvious benefits for the individual. Perhaps with the exception of studies on charitable giving (e.g., Oda \& Ichihashi, 2016), little is known about whether eye images can predict helping behavior towards complete strangers, in situations where direct rewards or reciprocation are unlikely.

The lost letter method has been one of the most appropriate approaches to study helping behavior that is directed towards unrelated others and confers negligible benefits upon the actor (Milgram, Mann, \& Harter, 1965; Shotland, Berger, \& Forsythe, 1970). Typically, a lost letter experiment focuses on the inclination to pick and post back a (seemingly lost) stamped letter that has been dropped on the pavement. Research suggests that lost letter return rates vary according to socio-economic status (SES), such that there are substantially higher return rates for high SES areas as compared to low SES areas (Holland, Silva, \& Mace, 2012; Nettle, Colléony, \& Cockerill, 2011). Based on this, in the present research we tested the watching eyes effect on the inclination to return a lost letter. Furthermore, we explored whether watching eyes have differential effects on lost letter return rates depending on the SES levels of the area where the letters are dropped.

\section{Methods}

(a)Procedure

\section{Experiment 1}

Four research assistants dropped 120 letters in two neighborhoods in Amsterdam in a single week in August 2011. The two neighborhoods were selected based on SES characteristics (A: "De Krommerdt" and B: "Ijburg West"). These neighborhoods were nearly identical in population size but the average housing price in A was substantially 
Table 1. Population size and average housing price per neighborhood in each of the three experiments Experiment 1

\begin{tabular}{|c|c|c|c|}
\hline SES & Neighborhood & Population Size & Average Housing Price \\
\hline High & Ijburg West & 11,670 & $€ 369,000$ \\
\hline Low & De Krommerdt & 11,945 & $€ 219,000$ \\
\hline \multicolumn{4}{|c|}{ Experiment 2} \\
\hline SES & Neighborhood & Population Size & Average Housing Price \\
\hline High & Ulgersmabuurt & 5,465 & $€ 239,000$ \\
\hline Low & Oost-Indische Buurt & 6,410 & $€ 140,000$ \\
\hline \multicolumn{4}{|c|}{ Experiment 3} \\
\hline SES & Neighborhood & Population Size & Average Housing Price \\
\hline \multirow{4}{*}{ High } & Apollobuurt & 8,525 & $€ 688,000$ \\
\hline & Willemspark & 5,555 & $€ 612,000$ \\
\hline & Museumkwartier & 11,405 & $€ 619,000$ \\
\hline & Grachtengordel-West & 6,985 & $€ 501,000$ \\
\hline \multirow{5}{*}{ Low } & Tuindorp Oostzaan & 10,510 & $€ 176,000$ \\
\hline & Tuindorp Nieuwendam & 3,395 & $€ 183,000$ \\
\hline & Volewijck & 9,360 & $€ 158,000$ \\
\hline & Tuindorp Buiksloot & 1,845 & $€ 172,000$ \\
\hline & De Kolenkit & 8,595 & $€ 177,000$ \\
\hline
\end{tabular}

Note. The information is based on CBS and Straatinfo.

lower than in B (Table 1, CBS, 2010; Straatinfo, 2010). The assistants received instructions on how to drop the letters (e.g., not close to a mailbox, not on the same street) and dropped the letters when the weather conditions were good (in line with Holland, et al., 2012). The envelopes were pre-stamped and had the logo of the Rijksuniversiteit Groningen. They were addressed to T.V. Pollet's Vrije Universiteit Amsterdam's address and contained a neutral letter. One third of the envelopes had printed eyes $(n=40)$, one-third flowers $(n=40)$, and one-third no stimulus $(n=$ 40). The stimulus size was $1.27 \times 4.23 \mathrm{~cm}$ and the envelope size was C5. The envelopes were dropped evenly (i.e., 60 envelopes in each of the two neighborhoods).

\section{Experiment 2}

This experiment mirrored Experiment 1. Three research assistants dropped 120 letters in two different neighborhoods in Groningen, a mid-sized city in the Netherlands in a single week in September 2011. As in Experiment 1, they received instructions on how to perform letter drops. The two neighborhoods (A: "OostIndische Buurt"; B: "Ulgersmabuurt"), which were very close to one another but separated by a canal, were selected based on proximity and SES. While the population sizes were roughly similar, neighborhood A was larger and had a lower average housing price than neighborhood B (Table 1).

\section{Experiment 3}

Four research assistants dropped 300 letters in 9 different neighborhoods in Amsterdam during May 2013. Four of these neighborhoods can be classified as higher SES (Apollobuurt, Willemspark, Museumkwartier and Grachtengordel-West) and the remaining five as lower SES (Tuindorp Oostzaan, Tuindorp Nieuwendam, Volewijck, Tuindorp Buiksloot and De Kolenkit). The average housing prices in 2013 for the higher SES neighborhoods were around triple that of the lower SES neighborhoods (Table 1). The total population of the higher SES neighborhoods was roughly similar to that of the lower SES neighborhoods $(32,470$ vs. 33,705 in 2013).

All envelopes had the logo of the Vrije Universiteit Manesi \& Pollet LEBS Vol. 8 No.1 (2017) 12-15
Amsterdam on them and a caption 'Research Department' underneath the printed logos. The letters were addressed to Z. Manesi. Half of the envelopes $(n=150)$ had printed eyes under the logo of the university and the other half ( $n$ $=150$ ) an image of flowers (control condition, Figure 1). The stimulus size was $1.80 \times 5.10 \mathrm{~cm}$ and the envelope size was $\mathrm{C} 5$. The envelopes contained a neutral message, were prepaid and did not need a stamp. The inside of the envelope was coded with numbers $(1=$ high SES, $2=$ low SES). We did not further differentiate among these 9 neighborhoods.

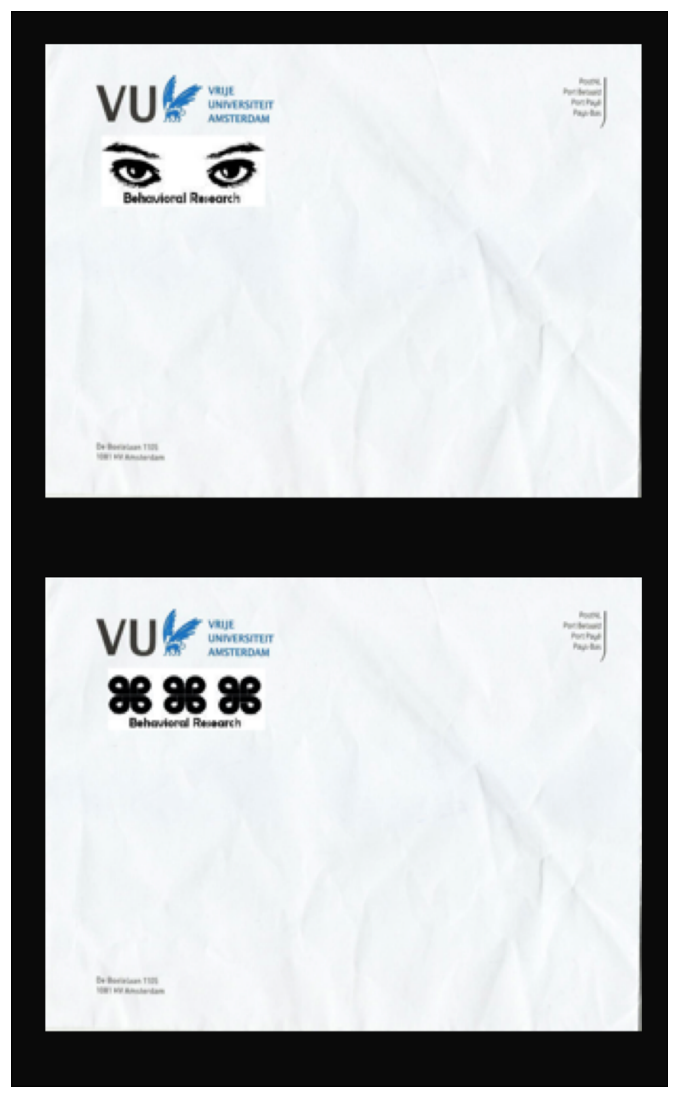

Figure 1. Example envelopes and stimuli used in the experiments. 
Half of the 300 letters $(n=150)$ were dropped in the lower SES neighborhoods (Tuindorp Oostzaan ( $n$ $=30)$, Tuindorp Nieuwendam $(n=30)$, Volewijck $(n=$ $30)$, Tuindorp Buiksloot $(n=30)$ and De Kolenkit $(n$ $=30))$ and the other half $(n=150)$ in the higher SES neighborhoods (Apollobuurt $(n=60)$, Willemspark $(n=$ $30)$, Museumkwartier $(n=30)$ and Grachtengordel-West $(n=30))$. The university's Ethics Committee approved the studies.

\section{(b)Statistical Analyses}

Our outcome measure is the number of letters returned (Figure 2). Analyses were conducted in R 3.2.1, we report chi-squared based tests for the individual studies. Cochran-Mantel-Haenszel (CMH) tests are used for the pooled analyses (Cochran, 1954; Mantel \& Haenszel, 1959). For this we chose flowers for studies 1 and 2, in order to compare to study 3. We also report Bayes Factors to quantify the support for the null hypotheses. As a crude guideline, Bayes Factors $<3$ are negligible evidence, between 3 to 20 can be considered positive evidence, $>20$ can be considered strong evidence, and $>150$ very strong evidence (Kass \& Raftery, 1995). Data and R code are available online in ESM 1.

\section{Results}

\section{Experiment 1}

There was no effect of neighborhood $\left(\chi^{2}(1,120)=2.727\right.$, $p=.099)$ or condition $\left(\chi^{2}(2,120)=0.606, p=.739\right)$ or the combination of both $\left(\chi^{2}(2,120)=2.37, p=.305\right)$ on the number of letters returned. Bayes factors suggest negligible evidence for the alternative hypothesis (2.320) for a neighborhood effect or a combination of both (1.444), and positive support for the null hypothesis for the eye effect (3.097). The total return rate was $45 \%$ and return rates for higher and lower SES neighborhoods were 53.33\% and $36.66 \%$ respectively.

\section{Experiment 2}

Neighborhood had a significant effect on return rate $\left(\chi^{2}\right.$ $(1,120)=4.432, p=.035$; Bayes Factor: 5.747). There were no effects for condition $\left(\chi^{2}(2,120)=0.897, p=.644\right.$; Bayes Factor in favor of null: 2.896$)$ or the combination of condition and neighborhood $\left(\chi^{2}(2,120)=0.947, p=\right.$ .623; Bayes Factor in favor of null: 1.794). The total return rate was $65 \%$ and return rates for higher and lower SES neighborhoods were $75 \%$ and $55 \%$ respectively.

\section{Experiment 3}

There were no effects of neighborhood $\left(\chi^{2}(1,300)=\right.$ $0.339, p=.560)$, condition $\left(\chi^{2}(1,300)=1.10, p=.294\right)$ or the combination of both $\left(\chi^{2}(1,300)=1.99, p=.158\right)$ on the number of letters returned. Bayes factors suggest negligible evidence for the null hypothesis (2.773) for a neighborhood effect and the eye effect (1.801) or a combination of both (1.444), and negligible support for the alternative hypothesis for a combination of both (1.003). The total return rate was $56.66 \%$ and return rates for higher and lower SES neighborhoods were $54.66 \%$ and $58.66 \%$ respectively.

\section{Pooled analysis}

When combining the data from the three experiments, the $\mathrm{CMH}$ tests showed no suggestion of an effect for neighborhood, eyes, or their combination (all $p$ 's >.3). Bayes factors suggest support for the null hypotheses over the alternative hypotheses with factors $2.6,82.8$ and 606, respectively. There is thus negligible evidence for the null for the SES effect, but strong evidence for the null for the watching eye effect or its combination with the SES effect.
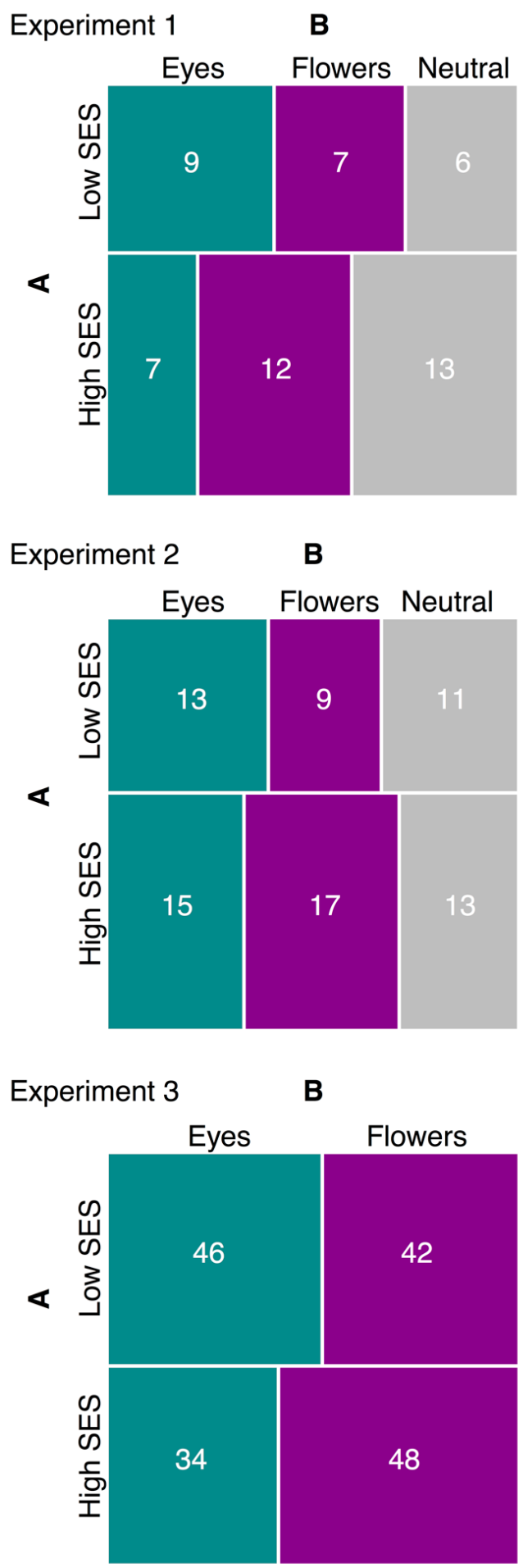

Figure 2. Lost letter return rates in three experiments according to condition and SES levels. 


\section{Discussion}

Combined analysis of three studies yielded no significant effect of eye images on lost letter return rates. Furthermore, we found no significant interaction between eye images and SES levels and no evidence for a link between an area's SES levels and lost letter return rates. These null findings suggest that eye images may not be a powerful tool to enhance forms of prosociality that entail certain costs and that do not confer apparent benefits to the actor. Being willing to go out of one's way to post the found letter requires certain amount of time and effort and may not confer social rewards (or sanctions) associated with more ordinary forms of prosociality (e.g., avoid littering, pay for one's drinks, wash one's hands, or recycle, see, e.g., Bateson et al., 2006). This null result is in line with meta-analytic findings indicating no effect of eye images on generosity (Northover et al., 2017). Furthermore, it hints at the possibility that the power of interventions based on eye images may depend on the form of prosociality.

Another implication is that eye images did not have differential effects on high versus low SES individuals, indicating no susceptibility to minimal cues to being watched based on one's socioeconomic status. The finding that an area's SES levels had no effect on lost letter return rates is in contrast to previous studies (Holland et al., 2012; Nettle et al., 2011). Considering that the present research was conducted in the Netherlands whereas both aforementioned studies were conducted in the UK may suggest that there are differences between countries in potential SES effects on prosociality - in terms of lost letter return rates. Future cross-country studies could shed light on this issue. Among the limitations of the present research is the fact that the envelopes had a university logo and that the recipient names were foreign. It is possible that these factors may have affected return rates. Yet, the names of those public institutions generally have neutral connotations and the recipient names were gender-neutral and devoid of potential social or minority connotations.

In conclusion, the null results of this research suggest that minimal cues to being watched may not be a powerful intervention to promote return of lost letters.

\section{Acknowledgments}

We thank all the research assistants involved for their assistance with the letter drops. This research was supported in part by the John Templeton Foundation.

\section{References}

Bateson, M., Nettle, D., \& Roberts, G. (2006). Cues of being watched enhance cooperation in a real-world setting. Biology Letters, 2, 412-414. (doi: 10.1098/ rsbl.2006.0509)

Bateson, M., Robinson, R., Abayomi-Cole, T., Greenlees, J., O'Connor, A., \& Nettle, D. (2015). Watching eyes on potential litter can reduce littering: evidence from two field experiments. PeerJ, 3, e1443. (doi: 10.7717/ peerj.1443)

CBS (2010). Centraal Bureau voor de Statistiek, CBS in uw buurt. Retrieved from http://www.cbsinuwbuurt. nl/ (last accessed on May 1 2017)

Cochran, W. G. (1954). Some methods for strengthening the common $\chi^{2}$ tests. Biometrics, 10, 417-451. (doi: 10.2307/3001616)

Holland, J., Silva, A. S., \& Mace, R. (2012). Lost letter measure of variation in altruistic behaviour in 20 neighbourhoods. PLoS ONE, 7, e43294. (doi: 10.1371/ journal.pone.0043294)

Kass, R. E., \& Raftery, A. E. (1995). Bayes Factors. Journal of the American Statistical Association, 90, 773-795. (doi: 10.1080/01621459.1995.10476572)

Mantel, N., \& Haenszel, W. (1959). Statistical aspects of the analysis of data from retrospective studies. Journal of the National Cancer Institute, 22, 719-748. (doi: 10.1093/jnci/22.4.719)

Milgram, S., Mann, L., \& Harter, S. (1965). The lost-letter technique: a tool of social research. Public Opinion Quarterly, 29, 437-438. (doi: 10.1086/267344)

Nettle, D., Colléony, A., \& Cockerill, M. (2011). Variation in cooperative behaviour within a single city. PLoS ONE, 6, e26922. (doi: 10.1371/journal.pone.0026922)

Nettle, D., Nott, K., \& Bateson, M. (2012). "Cycle thieves, we are watching you": impact of a simple signage intervention against bicycle theft. PloS One, 7, e51738. (doi: 10.1371/journal.pone.0051738)

Northover, S. B., Pedersen, W. C., Cohen, A. B., \& Andrews, P. W. (2017). Artificial surveillance cues do not increase generosity: two meta-analyses. Evolution and Human Behavior, 38, 144-153. (doi: 10.1016/ j.evolhumbehav.2016.07.001)

Oda, R., \& Ichihashi, R. (2016). The watching eyes effect on charitable donation is boosted by fewer people in the vicinity. Letters on Evolutionary Behavioral Science, 7, 9-12. (doi: 10.5178/lebs.2016.52)

Panagopoulos, C., \& Van der Linden, S. (2016). Conformity to implicit social pressure: the role of political identity. Social Influence, 11, 177-184. (doi: 10.1080/15534510.2016.1216009)

Powell, K. L., Roberts, G., \& Nettle, D. (2012). Eye images increase charitable donations: evidence from an opportunistic field experiment in a supermarket. Ethology, 118, 1096-1101. (doi: 10.1111/eth.12011)

Shotland, R. L., Berger, W. G., \& Forsythe, R. (1970). A validation of the lost-letter technique. Public Opinion Quarterly, 34, 278-281. (doi: 10.1086/267799)

Straatinfo (2010). Straatinfo: Alles over uw straat. Retrieved from straatinfo.nl/ (last accessed on May 1 2017)

Sparks, A., \& Barclay, P. (2013). Eye images increase generosity, but not for long: the limited effect of a false cue. Evolution and Human Behavior, 34, 317322. (doi: 10.1016/j.evolhumbehav.2013.05.001) 